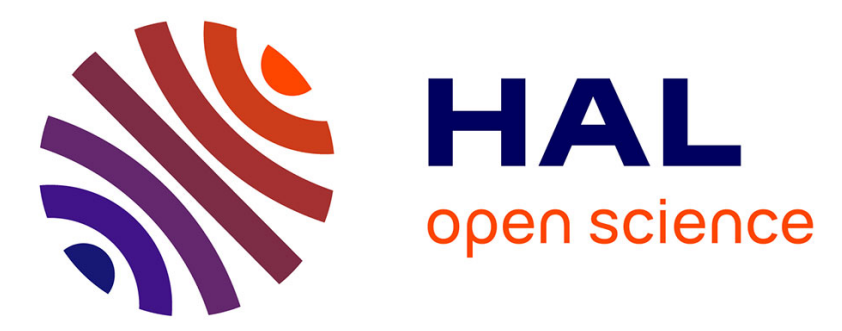

\title{
Biochemical characterization and mutational studies of a novel 3-methlyadenine DNA glycosylase II from the hyperthermophilic Thermococcus gammatolerans
}

Donghao Jiang, Likui Zhang, Kunming Dong, Yong Gong, Philippe Oger

\section{- To cite this version:}

Donghao Jiang, Likui Zhang, Kunming Dong, Yong Gong, Philippe Oger. Biochemical characterization and mutational studies of a novel 3-methlyadenine DNA glycosylase II from the hyperthermophilic Thermococcus gammatolerans. DNA Repair, 2021. hal-03035060

\author{
HAL Id: hal-03035060 \\ https://hal.science/hal-03035060
}

Submitted on 2 Dec 2020

HAL is a multi-disciplinary open access archive for the deposit and dissemination of scientific research documents, whether they are published or not. The documents may come from teaching and research institutions in France or abroad, or from public or private research centers.
L'archive ouverte pluridisciplinaire HAL, est destinée au dépôt et à la diffusion de documents scientifiques de niveau recherche, publiés ou non, émanant des établissements d'enseignement et de recherche français ou étrangers, des laboratoires publics ou privés. 


\section{Biochemical characterization and mutational studies of a novel 3-methlyadenine} DNA glycosylase II from the hyperthermophilic Thermococcus gammatolerans

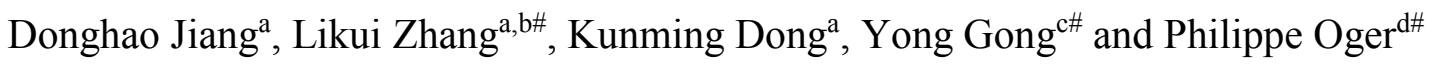

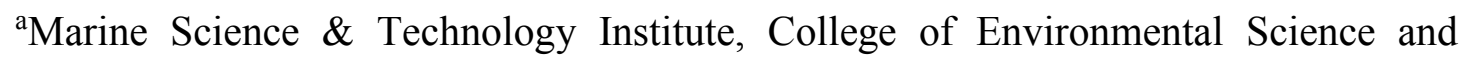
Engineering, Yangzhou University, China

${ }^{\mathrm{b}}$ Guangling College, Yangzhou University, China

${ }^{\mathrm{c} B e i j i n g ~ S y n c h r o t r o n ~ R a d i a t i o n ~ F a c i l i t y, ~ I n s t i t u t e ~ o f ~ H i g h ~ E n e r g y ~ P h y s i c s, ~ C h i n e s e ~}$

Academy of Sciences, China

dUniv Lyon, INSA de Lyon, CNRS UMR 5240, Lyon, France

The first corresponding author: Dr. Likui Zhang

E-mail address: 1kzhang@yzu.edu.cn

Tel: +86-514-89795882

Fax: $+86-514-87357891$

Corresponding author: Dr. Yong Gong

Email: yonggong@ihep.ac.cn

Corresponding author: Dr. Philippe Oger

Email: philippe.oger@insa-lyon.fr 
Abstract
The hyperthermophilic and radioresistant euryarchaeon Thermococcus gammatolerans encodes a putative 3-methlyadenine DNA glycosylase II (Tg-AlkA). Herein, we report biochemical characterization and catalytic mechanism of Tg-AlkA. The recombinant Tg-AlkA can excise hypoxanthine (Hx) and 1-methlyadenine (1-meA) from dsDNA with varied efficiencies at high temperature. Notably, Tg-AlkA is a bi-functional glycosylase, which is sharply distinct from all the reported AlkAs. Biochemical data show that the optimal temperature and $\mathrm{pH}$ of Tg-AlkA for removing Hx from dsDNA are ca. $70^{\circ} \mathrm{C}$ and ca.7.0-8.0, respectively. Furthermore, the Tg-AlkA activity is independent of a divalent metal ion, and $\mathrm{Mg}^{2+}$ stimulates the Tg-AlkA activity whereas other divalent ions inhibit the enzyme activity with varied degrees. Mutational studies show that the Tg-AlkA W204A and D223A mutants abolish completely the excision activity, thereby suggesting that residues W204 and D223 are involved in catalysis. Surprisingly, the mutations of W204, D223, Y139 and W256 to alanine in Tg-AlkA lead to the increased affinity for binding DNA substrate with varied degrees, suggesting that these residues are flexible for conformational change of the enzyme. Therefore, Tg-AlkA is a novel AlkA that can remove Hx and 1-meA from dsDNA, thus providing insights into repair of deaminated and alkylated bases in DNA from hyperthermophilic Thermococcus.

Keywords: Thermococcus gammatolerans, DNA glycosylase, deaminated DNA, alkylated DNA, base excision repair 


\section{Introduction}

A variety of endogenous and exogenous DNA damaging agents can lead to a chemically diverse spectrum of alkylated nucleobases, including 7-methylguanine (7-meG), 3-methyladenine (3-meA), 3-methylguanine (3-meG), $\mathrm{O}^{6}$-methylguanine $\left(\mathrm{O}^{6}-\mathrm{meG}\right)$ and 1-methyladenine (1-meA) [1]. It has been estimated that 7-meG and 3-meA represent 6,000 and 1,200 lesions per mammalian cell per day, respectively [2]. The exposure to various alkylating agents and carcinogens can cause a marked increase in the level of spontaneous and non-enzymatic methylations in human cells [3]. Such damages can disturb DNA replication and transcription [4], and pose a severe threat for the cell since they may be mutagenic or cytotoxic. Fortunately, cells have evolved a number of DNA repair strategies to remove these damages to maintain the integrity of DNA in all organisms, which includes base excision repair (BER) triggered by a DNA glycosylase or the direct reversal of the damage mediated by a methyltransferase.

BER is thought to be an important repair pathway for excising 3-meA and other $\mathrm{N}$-alkylated purines from DNA [5]. DNA glycosylase is the first BER enzyme that can hydrolyze the $\mathrm{N}$-glycosylic bond of the alkylated base, thus removing the damaged base and forming an abasic (AP) site in the DNA. The AP site is further repaired by the subsequent action of an AP specific endonuclease, a 5'-deoxyribose phosphate lyase, a DNA repair polymerase, and a DNA ligase to restore the correct DNA sequence by using the intact strand as a template. Besides BER, the direct

reversal of the damage by a DNA alkyltransferase or the iron-2-oxoglutarate 
dependent AlkB protein can be used to repair $\mathrm{O}^{6}$-meG and 1-meA [6-7].

The involvement of a DNA glycosylase in the removal of alkylated bases was first identified in Escherichia coli [8]. Since 3-meA is a major substrate for alkylated DNA glycosylases, these enzymes are generally designated as 3-meA DNA glycosylases. Currently, 3-meA DNA glycosylases have been divided into four types: 3-meA DNA glycosylase I, 3-meA DNA glycosylase II, AlkC and AlkD [9]. While E. coli 3-meA DNA glycosylase I (Tag) is a constitutively expressed DNA glycosylase [10], E.coli 3-meA DNA glycosylase II (AlkA) is induced upon exposure to alkylating agents [11]. Biochemical data suggest that Tag can only remove 3-meA and 3-meG from DNA, displaying narrow substrate specificity [12]. In contrast, AlkA has much wider substrate specificity, capable of excising methylated bases (3-meA, 3-meG, 7-meG, and $\mathrm{O}^{2}$-methylpyrimidines), the deaminated adenine hypoxanthine (Hx), the oxidized guanine (8oxoG) and thymine from DNA [13-17]. Although both Tag and AlkA can excise 3-meA from alkylated DNA, they have very low amino acid sequence homology. Recently, AlkC and AlkD have been identified as two novel 3-methyladenine DNA glycosylases from Bacillus cereus, specifically removing $\mathrm{N}$-alkylated bases rather than oxidized or deaminated base lesions in DNA [1].

Besides E. coli, AlkA is also distributed in archaea and eukaryotes, highlighting its importance for the removal of alkylated bases from DNA [18]. Saccharomyces cerevisiae methyadenine DNA glycosylase (Mag) and human alkyladenine DNA glycosylase (AAG) are homologous to E. coli AlkA [19]. Interestingly, E. coli AlkA can excise normal guanine, adenine, cytosine, and thymine from DNA whereas $S$. 
cerevisiae MAG and human AAG can only excise normal guanine from DNA [20]. Human AAG is a well-characterized mono-functional glycosylase which can remove alkylated purine bases, such as $1, \mathrm{~N}^{6}$-ethenoadenine ( $\left.\varepsilon \mathrm{A}\right), 3-\mathrm{meA}$ and 7-meG [21-23]. In addition to alkylated bases, human AAG recognizes and removes efficiently deaminated purines such as $\mathrm{Hx}$, oxanine and xanthine (16, 24-25). Like other glycosylases, human AAG employs the canonical nucleotide flipping mechanism to cleave the N-glycosidic bond [26].

The biochemical characterization and catalytic mechanisms of the eukaryotic and bacterial AlkAs have been elucidated, demonstrating the importance of AlkA in the protection against the mutagenic and toxic effects of alkylating agents. Although archaeal genomes harbor the AlkA gene, only a few archaeal AlkA have been reported so far. Currently, only one arcaheal AlkA has been characterized from the hyperthermophilic euryarchaeon Archaeoglobus fulgidus AlkA [27-30]. Thus, our understanding of the role and biochemical function of archaeal AlkA remains incomplete.

Thermococcus gammatolerans, which was isolated from samples obtained in a hydrothermal vent located in the Gulf of California [31], is a hyperthermophilic archaeon with an optimal growth temperature of $88^{\circ} \mathrm{C}$, and is the most radioresistant archaeon to date, fully withstanding a $5.0 \mathrm{kGy}$ dose of gamma irradiation without loss of viability [32]. The genome of $T$. gammatolerans encodes a putative DNA-3-methyladenine glycosylase II (Tg-AlkA, ACS33694) [32], belonging to HhH-GPD superfamily. In this work, we show that Tg-AlkA is a novel AlkA with 
bi-functional activity that can excise $\mathrm{Hx}$ and 1-meA from dsDNA at high temperature, thereby providing an alternative pathway for the repair of $\mathrm{Hx}$ and 1-meA in DNA in hyperthermophilic Archaea.

\section{Materials and methods}

\section{Cloning, expression, and purification of Tg-AlkA}

The genome of T. gammatolerans EJ3, which has been deposited as DSM 15229, encodes a putative 3-methyladenine DNA glycosylase II (Tg-AlkA) (GenBank accession number ACS33694). The Tg-AlkA gene was amplified with the Phusion

DNA polymerase (Thermo Scientific, Waltham, MA, USA) with two primers containing NdeI and HindIII restriction sites (Tg-AlkA F and Tg-AlkA R, Table 1) using the genomic DNA of T. gammatolerans as a template. The amplified PCR reaction was performed by denaturing DNA at $95^{\circ} \mathrm{C}$ for $3 \mathrm{~min}$ and followed by 34 cycles of $95^{\circ} \mathrm{C}$ for $30 \mathrm{~s}, 55^{\circ} \mathrm{C}$ for $30 \mathrm{~s}$, and $72^{\circ} \mathrm{C}$ for $1 \mathrm{~min}$, with a final extension step at $72^{\circ} \mathrm{C}$ for $5 \mathrm{~min}$. The amplified DNA product was cleaved and ligated into the vector pET-30a $(+)$ (Novagen, Merck, Darmstadt, Germany), thus forming a recombinant Tg-AlkA gene with a $6 \mathrm{x}$ His-tag at the C-terminus. The recombinant gene was verified by sequencing. The verified plasmid was then transformed by heat shock into E. coli BL21 (DE3) pLysS cells (Transgene, Beijing, China) for protein expression.

The expression strain E. coli harboring the Tg-AlkA gene was inoculated into LB medium with $100 \mu \mathrm{g} / \mathrm{mL}$ kanamycin and cultured at $37^{\circ} \mathrm{C}$. The Tg-AlkA gene was expressed by adding isopropyl thiogalactoside (IPTG) at a final concentration of 0.1 
$\mathrm{mM}$ when the $\mathrm{OD}_{600}$ of the culture reached 0.6. The culture was further incubated for about 10 hrs.

Cells were collected by centrifugation $\left(6,000 \times \mathrm{g}\right.$ for $15 \mathrm{~min}$ at $\left.25^{\circ} \mathrm{C}\right)$ and were resuspended in Ni column buffer A $(20 \mathrm{mM}$ Tris- $\mathrm{HCl} \mathrm{pH} 8.0,1 \mathrm{mM}$ dithiothreitol (DTT), $500 \mathrm{mM} \mathrm{NaCl}, 50 \mathrm{mM}$ imidazole, and 10\% glycerol). After the cells were disrupted by sonication on ice, the supernatant was collected into a $50-\mathrm{mL}$ tube by centrifugation $\left(16,000 \times \mathrm{g}\right.$ for $30 \mathrm{~min}$ at $\left.4^{\circ} \mathrm{C}\right)$. The collected supernatant was heated at $70^{\circ} \mathrm{C}$ for $20 \mathrm{~min}$ to remove non-thermostable $E$. coli proteins and then centrifuged at $16,000 \times \mathrm{g}$ for $30 \mathrm{~min}$ at $4^{\circ} \mathrm{C}$. The cleared heated supernatant was applied onto a HisTrap FF column (GE Healthcare, Uppsala, Sweden) and then the Tg-AlkA protein was purified with NCG ${ }^{\mathrm{TM}}$ Chromatography System (Bio-Rad, Hercules, CA, USA) by elution in a linear gradient of $50-500 \mathrm{mM}$ imidazole. The Tg-AlkA protein fractions were collected and their purity was verified by $12 \%$ SDS-PAGE. The gel was stained with Coomassie blue. Finally, the purified Tg-AlkA protein was stored at $-80^{\circ} \mathrm{C}$ after dialysis in a storage buffer containing $20 \mathrm{mM}$ Tris- $\mathrm{HCl} \mathrm{pH} 8.0,50 \mathrm{mM} \mathrm{NaCl}, 1 \mathrm{mM}$ DTT, and 50\% glycerol. The Tg-AlkA protein concentration was determined by measuring the absorbance at $280 \mathrm{~nm}$. The molar extinction coefficient of the Tg-AlkA protein is theoretically predicted to be $55,350 \mathrm{M}^{-1} \mathrm{~cm}^{-1}$.

\section{Construction, overexpression, and purification of the Tg-AlkA mutants}

By using the wild-type plasmid harboring Tg-AlkA gene, the Tg-AlkA Y139A, D223A, W204A and W256A mutants were constructed by site-directed mutagenesis as a template using a kit from Transgene (China) following the manufacturer's 
instructions. The sequences of the mutagenic primers are listed in Table 1. The Tg-AlkA mutant plasmids were verified by sequencing. The Tg-AlkA mutant proteins were overexpressed, purified and quantified as described above for the wild-type Tg-AlkA.

\section{DNA substrates}

Normal and damaged oligonucleotides containing Hx, 1-meA, 8oxoG-, AP-, and U (uracil) were synthesized by Sangon Biotech Company, China. The sequences of these oligonucleotides are summarized in Table 1. The Cy3-labeled oligonucleotides were annealed with the complementary oligonucleotides in buffer $(20 \mathrm{mM}$ Tris- $\mathrm{Cl} \mathrm{pH}$ 8.0 and $100 \mathrm{mM} \mathrm{NaCl}$ ) to prepare the Cy3-labeled DNA substrates. The annealing reactions were performed at $100^{\circ} \mathrm{C}$ for $3 \mathrm{~min}$, and cooled down slowly to room temperature.

\section{DNA glycosylase assays}

Unless stated otherwise, the standard DNA glycosylase assays of the Tg-AlkA activity were performed in reactions $(10 \mu \mathrm{L})$ containing $20 \mathrm{mM}$ Tris- $\mathrm{HCl} \mathrm{pH} 8.0,1$ mM DTT, 8\% glycerol, $100 \mathrm{nM} \mathrm{Cy3-labeled} \mathrm{DNA} \mathrm{and} 600 \mathrm{nM} \mathrm{Tg-AlkA}$ at $70^{\circ} \mathrm{C}$ for $30 \mathrm{~min}$. The reactions were stopped with $10 \mu \mathrm{L}$ of stop solution containing $98 \%$ formamide and $20 \mathrm{mM}$ EDTA. The reaction products were denatured at $95^{\circ} \mathrm{C}$ for 5 min and chilled rapidly on ice for $5 \mathrm{~min}$. The cleaved product was separated by running a denaturing $15 \%$ polyacrylamide gel containing $8 \mathrm{M}$ urea. The gels were scanned and visualized with a molecular image analyzer (PharosFx System, BioRad) after electrophoresis. The quantitative analysis was performed with ImageQuant 
software. All glycosylase assays were replicated three times.

\section{Biochemical characterization assays}

Using $100 \mathrm{nM} \mathrm{Hx}$-containing dsDNA as substrate, we investigated the optimal temperature of the Tg-AlkA activity in reactions $(10 \mu \mathrm{L})$ containing $600 \mathrm{nM}$ enzyme The reactions were carried out at $30,40,50,60,70,80$ and $90^{\circ} \mathrm{C}$ for $30 \mathrm{~min}$, and stopped and treated as described above.

To evaluate the thermostability of the enzyme, we heated the Tg-AlkA protein at $80,85,90$, and $95^{\circ} \mathrm{C}$ for $20 \mathrm{~min}$, respectively. The heated Tg-AlkA protein was employed to perform the glycosylase assays under the same conditions.

The optimal $\mathrm{pH}$ of Tg-AlkA activity was examined by performing the DNA glycosylase reactions under varied $\mathrm{pHs}$ ranging from 6.0 to 11.0. The desired $\mathrm{pHs}$ were prepared with five different buffers (all at $20 \mathrm{mM}$ concentrations): sodium phosphate- $\mathrm{NaOH}(\mathrm{pH} 6.0$ and $\mathrm{pH}$ 7.0), Tris- $\mathrm{HCl}(\mathrm{pH} 8.0)$, and Gly-NaOH (pH 9.0, $\mathrm{pH} 10.0$ and $\mathrm{pH} 11.0)$. The reactions were stopped and treated as described above.

The effects of divalent metal ions on Tg-AlkA activity were determined by performing the glycosylase reactions in the presence of $5 \mathrm{mM}$ of $\mathrm{Mg}^{2+}, \mathrm{Mn}^{2+}, \mathrm{Ca}^{2+}$, $\mathrm{Zn}^{2+}, \mathrm{Co}^{2+}, \mathrm{Ni}^{2+}$, or $\mathrm{Cu}^{2+}$. The reactions were stopped and treated as described above.

The effect of salinity on Tg-AlkA activity was examined by performing the glycosylase reactions with varied $\mathrm{NaCl}$ concentrations ranging from 50 to $1,000 \mathrm{mM}$. The reactions were stopped and treated as described above.

\section{Kinetic analysis}

The DNA glycosylase assays were performed under single-turnover conditions 
where $600 \mathrm{nM}$ wild-type Tg-AlkA and $200 \mathrm{nM} \mathrm{Hx}$-containing dsDNA were present at varying temperatures for various times. Data from the concentrations of the remaining substrate after DNA cleavage by Tg-AlkA were plotted to a single exponential decay equation using the program KaleidaGraph (Synergy Software):

$[$ Remaining substrate $]=\mathrm{A} \exp \left(-k_{\text {endo }} t\right)$

where $\mathrm{A}$ and $k_{\text {endo }}$ are the reaction amplitude and the cleavage rate, respectively.

\section{Substrate specificity assays}

To investigate substrate specificity of Tg-AlkA activity, various damaged DNA substrates were employed at $100 \mathrm{nM}$ each to perform the DNA glycosylase assays of the enzyme at $70^{\circ} \mathrm{C}$ for $30 \mathrm{~min}$. Samples were treated as described above.

\section{DNA-binding assays}

Electrophoresis mobility shift assays (EMSA) were employed to examine Tg-AlkA binding to $\mathrm{Hx}-$ and 1-meA-containing DNA. Binding assays were performed at $25^{\circ} \mathrm{C}$ for $10 \mathrm{~min}$ in buffer $(10 \mu \mathrm{L})$ including $100 \mathrm{nM}$ Cy3-labeled DNA, $20 \mathrm{mM}$ Tris- $\mathrm{HCl} \mathrm{pH}$ 8.0, $1 \mathrm{mM}$ DTT, 8\% glycerol, and Tg-AlkA with various protein concentrations. Samples were loaded into a $4 \%$ native polyacrylamide gel in $0.1 \times$ TBE (Tris-Borate-EDTA) buffer for electrophoresis. The Cy3-labeled DNA was visualized with a molecular image analyzer (Bio-Rad) and quantitated with ImageQuant software. The DNA binding assays were also repeated three times.

\section{Results}

\section{The genome of $T$. gammatolerans encodes a putative AlkA}

The gene TGAM_1192 in the genome of $T$. gammatolerans encodes a putative 
3-methlyadenine DNA glycosylase II (Tg-AlkA) with an accession number ACS33694, which is a base excision repair protein belonging to HhH-GPD superfamily. Sequence alignment of Tg-AlkA to other bacterial and eukaryotic AlkAs showed that Tg-AlkA displays 67\%, 75\%, 62\%, 64\%, 64\%, 29\%, 21\%, 20\%, and 19\% similarity with the AlkA homologues from Thermococcus barophilus, Thermococcus kodakarensis, Thermococcus sibiricus, Pyrococcus furiosus, Palaeococcus pacificus, A. fulgidus, S. cerevisiae, E. coli, and Homo sapiens, respectively. Furthermore, Tg-AlkA possesses several conserved amino acids residues in the conserved motifs present in the AlkA homologues from other archaea, bacteria and eukaryotes (Fig. 1A). Thus, Tg-AlkA resembles other AlkA homologues, which are capable of excising methylated and other damaged bases from DNA.

In this work, we cloned the Tg-AlkA gene into the pET-30a $(+)$ expression vector and expressed this gene in the E. coli BL21(DE3) pLysS cells. The recombinant Tg-AlkA protein with a $6 \mathrm{x}$ His-tag at its C-terminus was successfully expressed as a $\sim 32 \mathrm{kDa}$ protein (Fig. 1B). Following the sonication, heat treatment $\left(70^{\circ} \mathrm{C}\right.$ for $20 \mathrm{~min}$ ), and affinity chromatography with a $\mathrm{Ni}$ column, the recombinant Tg-AlkA protein was finally purified to homogeneity (Fig. 1B).

\section{Cleavage of Hx- and 1-meA-containing DNA by Tg-AlkA}

We investigated whether Tg-AlkA is able to excise Hx and 1-meA from DNA by performing the DNA cleavage reactions in the presence of these two substrates. Note that 3-meA-containing DNA and other methylated DNA were not available in our lab. As shown in Fig. 2A, the Hx-containing dsDNA was gradually degraded with 
increasing $\mathrm{Tg}$-AlkA protein concentrations at $70^{\circ} \mathrm{C}$. At $600 \mathrm{nM}, 93 \%$ cleavage was observed, suggesting that $\mathrm{Tg}$-AlkA can effectively excise $\mathrm{Hx}$ from dsDNA at high temperature. In contrast, no cleaved product was seen when using the Hx-containing ssDNA as substrate at $70^{\circ} \mathrm{C}$. Furthermore, no cleaved product was formed by Tg-AlkA when using normal dsDNA or ssDNA as substrate (Figs. 2C and 2D). Thus, Tg-AlkA can effectively remove $\mathrm{Hx}$ from dsDNA at high temperature.

Bedsides, we employed 1-meA-containing dsDNA as a substrate to determine whether Tg-AlkA can excise it from dsDNA at high temperature. As shown in Fig. 1E, the 1-meA-containing dsDNA substrate was gradually degraded by Tg-AlkA with increasing protein concentrations. However, Tg-AlkA exhibited lower cleavage efficiencies for 1-meA-containing dsDNA than for Hx-containing dsDNA at all tested protein concentrations. Similar to Hx-containing ssDNA cleavage, no cleaved product was generated by Tg-AlkA when using 1-meA-containing ssDNA as substrate. Thus, Tg-AlkA can excise 1-meA from dsDNA with lower efficiencies than $\mathrm{Hx}$ from dsDNA.

\section{Biochemical characterization of Tg-AlkA}

Since Tg-AlkA displays a higher efficiency for removing Hx from dsDNA than 1-meA from dsDNA, we employed $\mathrm{Hx}$-containing dsDNA as a substrate to investigate the biochemical characterization of the enzyme, including optimal temperature, thermostability, optimal $\mathrm{pH}$, metal ion requirement, and salt adaptation. As shown in Fig. 3A, we found that Tg-AlkA exhibits varied Hx excision efficiencies over the range of temperatures tested $\left(30\right.$ to $\left.90^{\circ} \mathrm{C}\right)$. Under our experimental conditions, 
the optimal temperature for $\mathrm{Tg}$-AlkA activity was observed at $70^{\circ} \mathrm{C}$, which is ten degrees lower than the optimal growth temperature of T. gammatolerans. Furthermore, we demonstrated that the heated Tg-AlkA retained $87 \%, 68 \%$, and $71 \%$ cleavage activity after a 20 min treatment at $80^{\circ} \mathrm{C}, 85^{\circ} \mathrm{C}$, and $90^{\circ} \mathrm{C}$ (Fig. 3B), respectively. In contrast, $20 \mathrm{~min}$ at $95^{\circ} \mathrm{C}$ completely abolished Tg-AlkA activity. Therefore, Tg-AlkA is a thermostable thermophilic glycosylase.

We show that Tg-AlkA is able to excise Hx from dsDNA in a $\mathrm{pH}$ range from 6.0 to 9.0 with varied efficiencies (Fig. 3C), displaying optimal activity at $\mathrm{pH}$ 7.0-8.0. No cleaved product was observed when the cleavage reactions were performed at $\mathrm{pH} 10$ and $\mathrm{pH} 11$.

Next, we also investigated the requirement for a divalent metal ion by Tg-AlkA. Control reactions performed with EDTA showed that Tg-AlkA possessed $63 \%$ cleavage activity (Fig. 3D). This is because EDTA chelates the divalent ions that can be co-purified with the protein, which might affect the enzyme conformation, and thus lead to the reduced cleavage efficiency. In fact in the reaction without the addition of a divalent ion and without EDTA, Tg-AlkA exhibited 80\% activity. With the addition of a divalent ion, $\mathrm{Mg}^{2+}$ stimulated the activity of Tg-AlkA whereas $\mathrm{Zn}^{2+}$ and $\mathrm{Cu}^{2+}$ almost completely inhibited the enzyme. In the presence of $\mathrm{Ca}^{2+}, \mathrm{Tg}-\mathrm{AlkA}$ retained similar activity as observed for the control reaction without a divalent ion, suggesting that this ion does not interact at all with the Tg-AlkA protein. In the presence of $\mathrm{Mn}^{2+}$, $\mathrm{Ni}^{2+}$ or $\mathrm{Co}^{2+}$, Tg-AlkA retained only $30 \sim 40 \%$ activity, suggesting that the Tg-AlkA activity can be partially inhibited by these ions. Overall, Tg-AlkA activity is 
essentially independent of a divalent ion, but it can be enhanced by $\mathrm{Mg}^{2+}$.

Last, we determined the effect of $\mathrm{NaCl}$ on Tg-AlkA activity. As shown in Fig. 3E, the Tg-AlkA activity was gradually inhibited by increasing $\mathrm{NaCl}$ concentrations. At $200 \mathrm{mM} \mathrm{NaCl}, \mathrm{Tg}-\mathrm{AlkA}$ retained only $41 \%$ cleavage activity. No cleavage activity was observed in the presence $\mathrm{NaCl}$ concentrations above $400 \mathrm{mM}$. Thus, these observations suggest that $\mathrm{NaCl}$ is not essential for Tg-AlkA activity and that high $\mathrm{NaCl}$ concentrations could inhibit the enzyme activity.

\section{Substrate specificity of Tg-AlkA}

As mentioned above, we demonstrated that Tg-AlkA is able to excise $\mathrm{Hx}$ and 1-meA from dsDNA at high temperature. Next, we investigated the substrate specificity of Tg-AlkA by employing various DNA substrates containing a $\mathrm{Hx}: \mathrm{N}(\mathrm{N}$ is A, T, C or G). As shown in Fig. 4A, Tg-AlkA displayed $60 \%, 53 \%$, and $63 \%$ cleavage percentage when using dsDNA substrates with $\mathrm{Hx}: \mathrm{C}, \mathrm{Hx}: \mathrm{G}$ and $\mathrm{Hx}: \mathrm{A}$, respectively. In contrast, Tg-AlkA displayed 95\% cleavage when using the dsDNA substrate with Hx:T, suggesting that Hx:T is the preferred substrate of Tg-AlkA. Since Hx:T in dsDNA is commonly formed by the deamination of adenine of an A:T pair in dsDNA, the highly effective cleavage of Hx:T-containing dsDNA by Tg-AlkA suggests that this enzyme might be responsible for removing Hx from dsDNA formed by adenine deamination.

Last, we tested whether Tg-AlkA can act on the dsDNA substrates containing $\mathrm{U}: \mathrm{G}, 8$ oxoG:C, or AP:T. No cleaved product was formed by Tg-AlkA when using any of these dsDNA substrates (Fig. 4B). Thus, Tg-AlkA is active to remove $\mathrm{Hx}$ and 
1-meA, but inactive on other damaged bases (U, 8oxoG or AP) in dsDNA.

\section{Mutational studies of Tg-AlkA}

To reveal the key amino acid residues in Tg-AlkA for catalysis, we mutated four residues in the enzyme that are located in the conserved motifs present in AlkA. We constructed the mutants Y139A, W204A, D223A, and W256A of Tg-AlkA by site-directed mutagenesis, and expressed and purified these mutant proteins as described for the wild-type protein (Fig. S1).

We used the Hx-containing dsDNA as substrate to determine the cleavage efficiencies of the Y139A, W204A, D223A, and W256A Tg-AlkA mutants. Compared to the wild-type protein, the Tg-AlkA Y139A mutant had reduced cleavage efficiency at all protein concentrations. However, no cleaved product was observed with the Tg-AlkA W204A and D223A mutants, suggesting that the mutations of W204 and D233 to alanine completely abolished the enzyme activity. In contrast, the Tg-AlkA W256A mutant displayed wild-type efficiency at protein concentrations of $400 \mathrm{nM}$ and $600 \mathrm{nM}$, thereby indicating that the mutation of W256 to alanine has only a marginal impact on enzyme activity. Therefore, our observations suggest that residues D233 and W204 in Tg-AlkA are essential for protein activity and that as proposed for other protein they are involved in the catalytic site for the removal of $\mathrm{Hx}$ from dsDNA.

\section{DNA-binding studies of the wild-type and mutant Tg-AlkAs}

To probe whether Tg-AlkA can bind $\mathrm{Hx}$ - and 1-meA-containing dsDNA, we performed EMSA by incubating the wild-type enzyme with Hx-containing or 
1-meA-containing dsDNA. As shown in Fig. 6A, the Hx-containing dsDNA substrate was gradually bound with increasing Tg-AlkA protein concentrations. At $10 \mu \mathrm{M}$, almost all the free Hx-containing dsDNA was bound by Tg-AlkA. Interestingly, Tg-AlkA displayed similar binding efficiencies for normal dsDNA and Hx-containing dsDNA (Fig. 6B). At $2.5 \mu \mathrm{M}$ and $5.0 \mu \mathrm{M}$, the binding of 1-meA-containing dsDNA was measured to be $44 \%$ and $87 \%$ (Fig. 6C), which is significantly higher than those measured for Hx-containing dsDNA. At $10 \mu \mathrm{M}$, Tg-AlkA showed similar binding efficiencies for Hx-containing dsDNA and 1-meA-containing dsDNA at $10 \mu \mathrm{M}$. Thus, Tg-AlkA exhibits effective DNA binding ability, no matter whether damaged or undamaged dsDNA is present.

Next, we investigated the dsDNA binding by the Tg-AlkA mutants. Surprisingly, almost all Hx-containing dsDNA was bound by the Tg-AlkA mutant W204A at 2.0 $\mu \mathrm{M}$ (Fig. 6E), suggesting that the mutation of W204 to alanine enables the enzyme to have extremely high affinity for Hx-containing dsDNA binding. Furthermore, the Tg-AlkA Y139A, D223A, and W256A mutants displayed higher than wild-type efficiencies for Hx-containing dsDNA binding at $2.5 \mu \mathrm{M}$ and $5.0 \mu \mathrm{M}$ (Figs. 6D, 6F, and $6 \mathrm{G})$, thereby indicating that the mutations of Y139, D223, and W256 to alanine also increase the binding to Hx-containing dsDNA. At $10 \mu \mathrm{M}$, the mutants Tg-AlkA Y139A, D223A, and W256A displayed binding efficiencies similar to the wild-type protein. Altogether, these observations suggest that the four residues W204, Y139, D223, and W256 in Tg-AlkA might play roles in maintaining the flexible conformation which is helpful for DNA binding. 


\section{Kinetic analysis of DNA cleavage by Tg-AlkA}

Under the single turnover condition where the enzyme concentration was three-fold higher than DNA concentration, we performed a time course experiment of DNA cleavage activity of Tg-AlkA at $70^{\circ} \mathrm{C}$. As shown in Fig. 7A, the Hx-containing dsDNA substrate was gradually cleaved as reaction time increased. Almost all the Hx-containing dsDNA substrate was degraded by Tg-AlkA after 20 min, thereby indicating that the enzyme has a strong activity for cleaving Hx-containing dsDNA.

The molar amount of the remaining DNA substrate in the DNA cleavage reactions catalyzed by Tg-AlkA was calculated at all the tested protein concentrations and plotted against reaction time. The $k_{\text {endo }}$ and $\mathrm{A}$ values were obtained by fitting a single-exponential decay equation (Fig. 7B). The $k_{\text {endo }}$ and A values for the wild-type protein were determined to be $0.19 \pm 0.013 \mathrm{~min}^{-1}$ and $206 \pm 4.2 \mathrm{nM}$, respectively.

\section{Discussion}

Genomic analysis has shown that 3-methlyadine DNA glycosylase II is widespread in bacteria, eukaryotes, and archaea, capable of excising Hx, 3-meA and other damaged bases from dsDNA. In this work, we provide for the first time biochemical data of one archaeal 3-methyladeine DNA glycosylase II from a Thermococcus species, demonstrating that Tg-AlkA is capable of excising $\mathrm{Hx}$ and 1-meA from dsDNA at high temperature. Further biochemical analysis suggests that Tg-AlkA displays higher efficiencies for removing $\mathrm{Hx}$ than 1-meA from dsDNA. Importantly, Tg-AlkA displays several distinct biochemical characteristics with the other reported AlkAs. 
Currently, all the reported 3-methyladenine DNA glycosylase II from bacteria, archaea and eukaryotes are mono-functional, which can only excise various types of alkylated DNA base or other deaminated base, thus leaving an AP site. Interestingly, we revealed that $\mathrm{Tg}$-AlkA is a bi-functional DNA glycosylase since it can not only excise $\mathrm{Hx}$ and 1-meA from dsDNA, but also cleave the generated AP site in a $\beta$-elimination or $\gamma$-elimination reaction manner [33]. Thus, Tg-AlkA is sharply distinct from all the reported mono-functional AlkAs.

Furthermore, our data demonstrate that Tg-AlkA can remove $\mathrm{Hx}$ and 1-meA from dsDNA but not from ssDNA, suggesting that the enzyme might be involved in repairing $\mathrm{Hx}$ and 1-meA in genomic DNA. In contrast, the E. coli AlkA can remove alkylated base from ssDNA [34]. Therefore, Tg-AlkA and E. coli AlkA vary greatly in the removal of alkylated bases or deaminated bases from ssDNA.

Hypoxanthine in DNA is mutagenic in cells since it has a strong ability to form mismatches. Replication of hypoxanthine in DNA before repaired would lead to AT to GC transition mutations [35]. Hypoxanthine in DNA can be removed by endonuclease $\mathrm{V}$, which is a highly conserved protein in all three domain organisms [36]. Besides endonuclease V, the AlkAs from human, rat, S. cerevisiae and E. coli can effectively excise hypoxanthine from DNA [16, 25, 37-38]. In this work, we demonstrate that Tg-AlkA has higher efficiencies for removing Hx than 1-meA from dsDNA, thereby indicating that the enzyme might be involved in repairing $\mathrm{Hx}$ in Theromoccus cells.

Thermostablilty is a common characteristic of proteins and enzymes of 
hyperthermophilies. As expected, the optimal temperature measured for Tg-AlkA to excise $\mathrm{Hx}$ from dsDNA is $70^{\circ} \mathrm{C}$, which is however ca. 10 degrees lower than the growth temperature of the protein host. Nevertheless, the optimal temperature of Tg-AlkA is 10 degrees higher than that of A. fulgidus AlkA [28], which growth temperature is similar to that of T. gammatolerans. In addition, Tg-AlkA still retains a significant activity after $20 \mathrm{~min}$ heating at $90^{\circ} \mathrm{C}$, indicating that the Tg-AlkA protein is thermostable, resembling other proteins or enzymes from Thermococcus species.

AlkAs display varied $\mathrm{pH}$ requirements for their activity. For Tg-AlkA the optimal activity is observed over a broad $\mathrm{pH}$ range from 7.0 to 8.0. No activity is detected for Tg-AlkA at highest $\mathrm{pH}$ of 10.0 and 11.0. This might be because DNA duplexes can be denatured under strong alkaline conditions, and that Tg-AlkA cannot act on Hx-containing ssDNA. In contrast, the A. fulgidus AlkA has an optimal pH of 5.0 for the removal of Hx from dsDNA [28].

The Tg-AlkA activity is independent of a divalent ion, which is consistent with what was observed for the A. fulgidus AlkA activity [28]. However, $\mathrm{Mg}^{2+}$ stimulates the Tg-AlkA activity, which was also observed for the A. fulgidus AlkA. In contrast to the A. fulgidus AlkA, $\mathrm{Zn}^{2+}$ inhibits the Tg-AlkA activity when it was shown to stimulate that of A. fulgidus AlkA. $\mathrm{Ca}^{2+}$ was shown to have no impact on the activity of Tg-AlkA similar to what was observed for the A. fulgidus AlkA. While, $\mathrm{Mn}^{2+}$ has no effect on the A. fulgidus AlkA activity, it inhibited Tg-AlkA activity. Thus, the metal requirement of Tg-AlkA and the A. fulgidus AlkA show similarities and divergences. 
In contrast to the A. fulgidus AlkA, the Tg-AlkA activity is significantly inhibited by $\mathrm{NaCl}$ with above $200 \mathrm{mM}$, while the former still retains approximately $90 \%$ cleavage activity at $200 \mathrm{mM}$ [28]. Even at $400 \mathrm{mM} \mathrm{NaCl}$, the A. fulgidus AlkA still retains ca. $20 \%$ cleavage activity while the Tg-AlkA only possesses $3.5 \%$ cleavage activity. These observations suggest that the Tg-AlkA is less salt-tolerant than the $A$. fulgidus AlkA.

Tg-AlkA can remove Hx from dsDNA with a strong preference for dsDNA substrates with Hx:T, over ones with Hx:C, Hx:A and Hx:G. In contrast, E. coli AlkA excises Hx from dsDNA with Hx:A with the highest efficiencies, followed by I:T > I:C> I:G [16]. The A. fulgidus AlkA exhibits a substrate specificity in the order: Hx:G > Hx:T > Hx:C > Hx:A, which contrasts sharply with that of Tg-AlkA [28]. Thus, it is likely that Tg-AlkA is responsible for the excision of Hx from dsDNA within Hx:T pairs. Last, Tg-AlkA cannot eliminate normal bases, 8oxoG, U and AP from dsDNA, thereby indicating that the enzyme can specifically remove $\mathrm{Hx}$ and alkylated bases from dsDNA.

Similar to 3-meC, the highly toxic 1-meA is also a major product in DNA [39]. Fortunately, 1-meA in DNA can be repaired by oxidative demethylation, which is catalyzed by the AlkB protein and homologues in E. coli and mammals [29, 40-42]. However, no AlkB homologue has been identified in Archaea, thereby addressing a question how archaea repair 1-meA in DNA. Leiros et al revealed that A. fulgidus AlkA can remove effectively 1-meA from DNA [30], thus providing a pathway for the repair of 1-meA in DNA in archaeal cells. In this work, our data demonstrate that 
Tg-AlkA is also able to excise 1-meA from dsDNA, thus further confirming the role of archaeal AlkA in repair of 1-meA in DNA.

Biochemical and structural data on E. coli AlkA provide insights into its alkylated base recognition and removal [43-48], suggesting that E. coli AlkA is a well-characterized alkylated DNA glycosylase. Structural data show that AlkA is a structural homolog of endonuclease III [49], possessing a signature DNA-binding motif that comprises a helix-hairpin-helix $(\mathrm{HhH})$ with the consensus sequence Leu/Phe-Pro-Gly-Val/Ile-Gly, followed by an invariant Asp 20 residues later [50]. Thus, AlkA is classified in the HhH-GPD superfamily. Biochemical data show that a mutation of D238 to alanine in E. coli AlkA abolishes totally the activity, suggesting that residue D238 is a catalytic residue of the enzyme [45]. Furthermore, residue D240 of A. fulgidus AlkA, which is analogous to residue D238 of E. coli AlkA, has been verified to be a key catalytic residue [30]. Similarly, Helicobacter pylori AlkA D150N mutant retains 4\% activity [51]. This residue corresponds to D203 in Tg-AlkA. In this work, our mutational study showed that a mutation of residue D203 to alanine totally abolishes the activty of Tg-AlkA, thereby confirming that the conserved Asp residue in the HhH-GPD motif is a catalytic residue also in Tg-AlkA.

In addition to residue D238, residue W218 in E. coli AlkA is thought to be located behind the ribose of the flipped out nucleotide [26], leaving no room for a water nucleophile. Interestingly, we demonstrate that residue W204 in Tg-AlkA, which is analogous to the residue W218, is a key residue for catalysis since the mutation of W204 to alanine leads to loss of the enzyme activity, without loss of 
DNA binding efficiency.

Besides clarifying the function of residues D223 and W204 of Tg-AlkA, we also deciphered the function of residues Y139 and W256 of the enzyme. Our data show that residues Y139 and W256 are not catalytic residues, but are important for the flexibility of the protein and for conformational changes since these mutants display increased affinities for Hx-containing dsDNA. In addition, the D233A and W204A mutants have higher efficiencies for binding to $\mathrm{Hx}$-containing dsDNA than the wild-type protein, which also suggests that residues D233 and W204 may also be in conformational change, and not only in catalysis.

In conclusion, we investigated biochemical characteristics of the 3-methyladeine DNA glycosylase II from the hyperthermophilic and radioresistant euryarchaeon $T$. gammatolerans and probed the function of four residues of the enzyme. Interestingly, Tg-AlkA is a bi-functional glycosylase that can remove $\mathrm{Hx}$ and 1-meA from dsDNA at high temperature. The optimal temperature and optimal $\mathrm{pH}$ of $\mathrm{Tg}$-AlkA are $70^{\circ} \mathrm{C}$ and 7.0-8.0, respectively. Furthermore, Tg-AlkA is independent of a divalent metal ion for its activity but is stimulated by $\mathrm{Mg}^{2+}$. The enzyme prefers the duplex substrates in the order: $\mathrm{Hx}: \mathrm{T}>\mathrm{Hx}: \mathrm{C}>\mathrm{Hx}: \mathrm{A}>\mathrm{Hx}: \mathrm{G}$. Mutational studies suggest that residues D223 and W204 are involved in catalysis, and residues D223, Y139A, W204 and W256 are flexible for conformational change.

\section{Acknowledgments}

We thank Prof. Fabrice Confalonieri at University of Paris-Sud for providing the genomic DNA of T. gammatolerans EJ3. 


\section{Author contributions}

LZ, YG and PO designed experiments; DJ and KD performed experiments; LZ, YG and PO analyzed data; LZ, YG and PO wrote and revised the paper.

\section{Funding information}

This work was supported by the Provincial Natural Science Foundation of Jiangsu Province (No. BK20191219), High Level Talent Support Program of Yangzhou University and the Academic Leader of Middle and Young People of Yangzhou University Grant.

\section{Conflict of interest}

The authors declare that they have no conflict of interest.

\section{Ethical statement}

This article does not contain any studies with human participants or animals performed by any of the authors.

\section{References}

[1] Alseth, T. Rognes, T. Lindbäck, I. Solberg, K. Robertsen, K.I. Kristiansen, D. Mainieri, L. Lillehagen, A.B. Kolstø, M. Bjørås, A new protein superfamily includes two novel 3-methyladenine DNA glycosylases from Bacillus cereus, AlkC and AlkD, Mol. Microbiol. 59 (2006) 1602-1609.

[2] E. C. Friedberg, G.C. Walker, W. Siede, R.D. Wood, R.A. Schultz, T. Ellenberger, DNA Repair and Mutagenesis, Second Edition, ASM Press, 2006.

[3] C. Zhao, M. Tyndyk, I. Eide, K. Hemminki, Endogenous and background DNA adducts by methylating and 2-hydroxyethylating agents, Mutat. Res. 424 (1999) 
$117-125$.

[4] K. Larson, J. Sahm, R. Shenkar, B. Strauss, Methylation-induced blocks to in vivo DNA replication, Mutat. Res. 150 (1985) 77-84.

[5] E. Seeberg, K.G. Berdal, Repair of alkylation damage to DNA. In Base Excision Repair of DNA Damage. Hickson, I.D. (ed.). Georgetown, TX: Landes Bioscience, (1997) 151-168.

[6] P.O. Falnes, R. Johansen, E. Seeberg, AlkB mediated oxidative demethylation of reverses DNA damage in Escherichia coli, Nature 419 (2002) 178-182.

[7] S.C. Trewick, T.F. Henshaw, R.P. Hausinger, T. Lindahl, B. Sedgwick, Oxidative demethylation by Escherichia coli AlkB reverts DNA base damage, Nature 419 (2002) 174-178.

[8] T. Lindahl, New class of enzymes acting on damaged DNA, Nature 259 (1976) 64-66.

[9] M.D. Wyatt, J.M. Allan, A.Y. Lau, T.E. Ellenberger, L.D. Samson, 3-methyladenine DNA glycosylases: structure, function, and biological importance, Bioessays 21 (1999) 668-676.

[10]A.H. Metz, T. Hollis, B.F. Eichman, DNA damage recognition and repair by 3-methyladenine DNA glycosylase I (TAG), EMBO J. 26 (2007) 2411-2020.

[11]G. Evensen, E. Seeberg, Adaptation to alkylation resistance involves the induction of a DNA glycosylase, Nature 296 (1982) 773-775.

[12]S. Bjelland, M. Bjoras, E. Seeberg, Excision of 3-methylguanine from alkylated DNA by 3-methyladenine DNA glycosylase I of Escherichia coli, Nucleic Acids 
Res. 21 (1993) 2045-2049.

[13]P. Karran, T. Hjelmgren, T. Lindahl, Induction of a DNA glycosylase for $\mathrm{N}$-methylated purines is part of the adaptive response to alkylating agents, Nature 296 (1982) 770-773.

[14]T.V. McCarthy, P. Karran, T. Lindahl, Inducible repair of O-alkylated DNA pyrimidines in Escherichia coli, EMBO J. 3 (1984) 545-550.

[15]S. Bjelland, N.K. Birkeland, T. Benneche, G. Volden, E. Seeberg, DNA glycosylase activities for thymine residues oxidized in the methyl group are functions of the AlkA enzyme in Escherichia coli, J. Biol. Chem. 269 (1994) 30489-30495.

[16]M. Saparbaev, J. Laval, Excision of hypoxanthine from DNA containing dIMP residues by the Escherichia coli, yeast, rat, and human alkylpurine DNA glycosylases, Proc. Natl. Acad. Sci. U.S.A. 91 (1994): 5873-5877.

[17]M. Saparbaev, K. Kleibl, J. Laval, Escherichia coli, Saccharomyces cerevisiae, rat and human 3-methyladenine DNA glycosylases repair 1,N6-ethenoadenine when present in DNA, Nucleic Acids Res. 23 (1995) 3750-3755.

[18]A. Memisoglu, L. Samson, DNA repair functions in heterologous cells, Crit. Rev. Biochem. Mol. Biol. 31 (1996) 405-447.

[19]J. Chen, B. Derfler, L. Samson, Saccharomyces cerevisiae 3-methyladenine DNA glycosylase has homology to the AlkA glycosylase of E. coli and is induced in response to DNA alkylation damage, EMBO J. 9 (1990) 4569-4575.

[20]K.G. Berdal, R.F. Johansen, E. Seeberg, Release of normal bases from intact 
DNA by a native DNA repair enzyme, EMBO J. 17 (1998) 363-367.

[21]B. Hang, B. Singer, G.P. Margison, R.H. Elder, Targeted deletion of alkylpurine-DNA-N-glycosylase in mice eliminates repair of 1,N6-ethenoadenine and hypoxanthine but not of 3,N4-ethenocytosine or 8-oxoguanine, Proc. Natl. Acad. Sci. U.S.A. 94 (1997) 12869-12874.

[22]T.R. O'Connor, Purification and characterization of human 3-methyladenine-DNA glycosylase, Nucleic Acids Res. 21 (1993) 5561-5569.

[23]B. Singer, A. Antoccia, A.K. Basu, M.K. Dosanjh, H. Fraenkel-Conrat, P.E. Gallagher, J.T. Kusmierek, Z.H. Qiu, B..Rydberg, Both purified human 1,N6-ethenoadenine-binding protein and purified human 3-methyladenine-DNA glycosylase act on 1,N6-ethenoadenine and 3-methyladenine, Proc. Natl. Acad. Sci. U.S.A. 89 (1992) 9386-9390.

[24]T.M. Hitchcock, L. Dong, E.E. Connor, L.B. Meira, L.D. Samson, M.D. Wyatt, W. Cao. Oxanine DNA glycosylase activity from mammalian alkyladenine glycosylase, J. Biol Chem. 279 (2004) 38177-38183.

[25]G. Dianov, T. Lindahl, Preferential recognition of I. T base-pairs in the initiation of excision-repair by hypoxanthine-DNA glycosylase, Nucleic Acids Res. 19 (1991) 3829-3833.

[26]T. Hollis, Y. Ichikawa, T. Ellenberger, DNA bending and a flip-out mechanism for base excision by the helix-hairpin-helix DNA glycosylase, Escherichia coli AlkA, EMBO J. 19 (2004) 758-766.

[27]N.K. Birkeland, H. Anensen, I. Knaevelsrud, W. Kristoffersen, M. Bjørås, F.T. 
Robb, A. Klungland, S. Bjelland, Methylpurine DNA glycosylase of the hyperthermophilic archaeon Archaeoglobus fulgidus, Biochemistry 41 (2002) 12697-12705.

[28]C. Mansfield, S.M. Kerins, T.V. McCarthy, Characterisation of Archaeglobus fulgidus AlkA hypoxanthine DNA glycosylase activity, FEBS Lett. 540 (2003) $171-175$

[29]Leiros, M.P. Nabong, K. Grøsvik, J. Ringvoll, G.T. Haugland, L. Uldal, K. Reite, I.K. Olsbu, I. Knaevelsrud, E. Moe, O.A. Andersen, N.K. Birkeland, P. Ruoff, A. Klungland, S. Bjelland, Structural basis for enzymatic excision of N1-methyladenine and N3-methylcytosine from DNA, EMBO J. 26 (2007) 2206-2217.

[30]E. Jolivet, S. L'Haridon, E. Corre, P. Forterre, D. Prieur, Thermococcus gammatolerans sp nov., a hyperthermophilic archaeon from a deep-sea hydrothermal vent that resists ionizing radiation, Int. J. Syst. Evol. Microbiol. 53 (2003) 847-851.

[31]Y. Zivanovic, J. Armengaud, A. Lagorce, C. Leplat, P. Guerin, M. Dutertre, V. Anthouard, P. Forterre, P. Wincker, F. Confalonieri, Genome analysis and genome-wide proteomics of Thermococcus gammatolerans, the most radioresistant organism known amongst the Archaea, Genome Biol. 10 (2009) R70.

[32] Scharer, J. Jiricny, Recent progress in the biology, chemistry and structural biology of DNA glycosylases, Bioessays 23 (2001) 270-281. 
[33]J.C. Fromme, A. Banerjee, G.L.Verdine, DNA glycosylase recognition and catalysis, Curr. Opin. Struct. Biol. 14 (2004) 43-49.

[34]S. Bjelland, E. Seeberg, Different efficiencies of the Tag and AlkA DNA glycosylases from Escherichia coli in the removal of 3-methyladenine from single-stranded DNA, FEBS Lett. 397 (1996) 127-129.

[35]M. Hill-Perkins, M.D. Jones, P. Karran, Site-specific mutagenesis in vivo by single methylated or deaminated purine bases, Mutat. Res. 162 (1986) 153-163.

[36]W.G. Cao, Endonuclease V: an unusual enzyme for repair of DNA deamination, Cell. Mol. Life Sci. 70 (2013) 3145-3156.

[37]M. Saparbaev, J.C. Mani, J. Laval, Interactions of the human, rat, Saccharomyces cerevisiae and Escherichia coli 3-methyladenine-DNA glycosylases with DNA containing dIMP residues, Nucleic Acids Res. 28 (2000) 1332-1339.

[38]B. Zhao, P.J. O'Brien, Kinetic mechanism for the excision of hypoxanthine by Escherichia coli AlkA and evidence for binding to DNA ends, Biochemistry 50 (2011) 4350-4359.

[39]D.T. Beranek, Distribution of methyl and ethyl adducts following alkylation with monofunctional alkylating agents, Mutat. Res. 231 (1990) 11-30.

[40]T. Duncan, S.C. Trewick, P. Koivisto, P.A. Bates, T. Lindahl, B. Sedgwick, Reversal of DNA alkylation damage by two human dioxygenases, Proc. Natl. Acad. Sci. U.S.A. 99 (2002) 16660-16665.

[41]S.C. Trewick, T.F. Henshaw, R.P. Hausinger, T. Lindahl, B. Sedgwick, Oxidative demethylation by Escherichia coli AlkB directly reverts DNA base damage, 
Nature 419 (2002) 174-178.

[42]P.A. Aas, M. Otterlei, P.Ø. Falnes, C.B. Va ${ }^{\circ}$ gbø, F. Skorpen, M. Akbari, O. Sundheim, M. Bjøra ${ }^{\circ}$, G. Slupphaug, E. Seeberg, H.E. Krokan, Human and bacterial oxidative demethylases repair alkylation damage in both RNA and DNA, Nature 421 (2003) 859-863.

[43]P.J. O'Brien, T. Ellenberger, The Escherichia coli 3-methyladenine DNA glycosylase AlkA has a remarkably versatile active site, J. Biol. Chem. 279 (2004) 26876-26884.

[44]Y. Nakabeppu, H. Kondo, M. Sekiguchi, Cloning and characterization of the alkA gene of Escherichia coli that encodes 3-methyladenine DNA glycosylase II, J Biol Chem. 259 (1984) 13723-13729.

[45]Y. Yamagata, M. Kato, K. Odawara, Y. Tokuno, Y. Nakashima, N. Matsushima, K. Yasumura, K. Tomita, K. Ihara, Y. Fujii, Y. Nakabeppu, M. Sekiguchi, S. Fujii, Three-dimensional structure of a DNA repair enzyme, 3-methyladenine DNA glycosylase II from Escherichia coli, Cell 86 (1996) 311-319.

[46]S. Bjelland, E. Seeberg, Different efficiencies of the Tag and AlkA DNA glycosylases from Escherichia coli in the removal of 3-methyladenine from single-stranded DNA, FEBS Lett. 397 (1996) 127-129.

[47]J. Labahn, O.D. Schärer, A. Long, K. Ezaz-Nikpay, G.L. Verdine, T.E. Ellenberger, Structural basis for the excision repair of alkylation-damaged DNA, Cell 86 (1996) 321-329.

[48]M. Teale, J. Symersky, L. DeLucas, 3-methyladenine-DNA glycosylase II: the 
crystal structure of an AlkA-hypoxanthine complex suggests the possibility of product inhibition, Bioconjug. Chem. 13(2002) 403-407.

[49]R.P. Cunningham, H. Ahern, D. Xing, M.M. Thayer, J.A. Tainer, Structure and function of Escherichia coli endonuclease III, Ann. NY Acad. Sci. 726 (1994) 215-222.

[50]N.A. Kuznetsov, O.S. Fedorova, Kinetic Milestones of damage recognition by DNA glycosylases of the helix-hairpin-helix structural superfamily, Adv. Exp. Med. Biol. 1241 (2020) 1-18.

[51]B.F. Eichman, E.J. O'Rourke, J.P. Radicella, T. Ellenberger, Crystal structures of 3-methyladenine DNA glycosylase MagIII and the recognition of alkylated bases, EMBO J. 22 (2003) 4898-4909. 


\section{Figure legends}

Fig. 1. The genome of $T$. gammatolerans encodes a putative 3-methyladenine

DNA glycosylase II. A. Sequence alignment of 3-methyladenine DNA glycosylase II from archaea, bacteria and eukaryotes. Tga: Thermococcus gammatolerans (NCBI reference sequence: ACS33694); Tba: Thermococcus barophilus (NCBI reference sequence: WP_056933861); Tko: Thermococcus kodakarensis (UniProtKB reference sequence: Q5JG19); Tsi: Thermococcus sibiricus (UniProtKB reference sequence: C6A294); Pfu: Pyrococcus furiosus (UniProtKB reference sequence: Q8U3F7); Ppa: Palaeococcus pacificus (UniProtKB reference sequence: A0A075LXP7); Afu: Archaeoglobus fulgidus (UniProtKB reference sequence: O28163); Sce: Saccharomyces cerevisiae (NCBI reference sequence: GAX71061); Eco: Escherichia coli (NCBI reference sequence: AAA23430); Hsa: Homo sapiens (NCBI reference sequence: AAA58627). Similar or conserved amino acid residues are colored and boxed. B. Expression and purification of Tg-AlkA. The Tg-AlkA protein was over-expressed with IPTG and purified by sonication, heat treatment $\left(70^{\circ} \mathrm{C}\right.$ for $\left.20 \mathrm{~min}\right)$ and Ni column affinity purification.

Fig. 2. DNA cleavage by Tg-AlkA. DNA cleavage reactions were performed with 200, 400 and $600 \mathrm{nM} \mathrm{Tg-AlkA}$ at $70^{\circ} \mathrm{C}$ for 30 min using various DNA substrates. The cleaved products were analyzed by a SDS-PAGE. CK: reaction without the enzyme. A. Cleavage of Hx-containing dsDNA. B. Cleavage of Hx-containing ssDNA. C. Cleavage of normal dsDNA. D. Cleavage of normal ssDNA. E. Cleavage of 1-meA-containing dsDNA. F. Cleavage of 1-meA-containing ssDNA. 
Fig. 3. Biochemical properties of Tg-AlkA. The Hx-containing dsDNA cleavage reactions were performed under various conditions. The cleaved products were analyzed by a SDS-PAGE. CK: reaction without the enzyme; CK1 in panel B: reaction with unheated enzyme; CK1 in panel D: the reaction without a divalent cation. A. The optimal temperature of the enzyme activity; B. The thermo-tolerance of the enzyme; $\mathrm{C}$. The optimal $\mathrm{pH}$ of the enzyme activity; $\mathrm{D}$. The effects of divalent cations on the enzyme activity; $\mathrm{E}$. The effect of $\mathrm{NaCl}$ on the enzyme activity.

Fig. 4. Substrate specificity of Tg-AlkA. A. The Hx-containing dsDNA (Hx:T, Hx:A, $\mathrm{Hx}: \mathrm{G}$ and $\mathrm{Hx}: \mathrm{C}$ ) cleavage reactions of $600 \mathrm{nM}$ Tg-AlkA were performed at $70^{\circ} \mathrm{C}$ for $30 \mathrm{~min}$. B. The $80 x o G-$, U-, and AP-containing dsDNA cleavage reactions of $600 \mathrm{nM}$ Tg-AlkA were performed at $70^{\circ} \mathrm{C}$ for $30 \mathrm{~min}$. The cleaved products were analyzed by running a denaturing polyacrylamide gel. $\mathrm{CK}$ : the reaction without the enzyme.

Fig. 5. Cleavage of Hx-containing dsDNA by the Tg-AlkA mutants. One hundred nanomolars Hx-containing dsDNA was used as the substrate to determine the wild-type and mutant Tg-AlkAs activities at $70^{\circ} \mathrm{C}$ for $10 \mathrm{~min}$. Reaction products were detected by electrophoresis. A. The Y139A mutant. B. The W204A mutant. C. The D223A mutant. D. The W256A mutant. CK: the reaction without the enzyme.

Fig. 6. DNA-binding of the wild-type and mutant Tg-AlkAs. Various dsDNA substrates were incubated with the wild-type and mutant Tg-AlkAs with varied concentrations at $25^{\circ} \mathrm{C}$ for $10 \mathrm{~min}$. The bound product was run by electrophoresis. A. Hx-containing dsDNA binding of the wild-type protein. B. Normal dsDNA binding of the wild-type protein. C. 1-meA-containing dsDNA binding of the wild-type protein. 
D. Hx-containing dsDNA binding of the Y139A mutant. E. Hx-containing dsDNA binding of the W204A mutant. F. Hx-containing dsDNA binding of the D223A mutant. G. Hx-containing dsDNA binding of the W256A mutant. CK: the binding assay without the enzyme.

Fig. 7. Kinetic analysis of DNA cleavage by $\mathbf{T g}$-AlkA at $70^{\circ} \mathrm{C}$. DNA cleavage reactions by Tg-AlkA were performed under the single turnover condition for various times $(10 \mathrm{~s}-30 \mathrm{~min})$ at $70^{\circ} \mathrm{C}$. A. Hx-containing dsDNA cleavage by Tg-AlkA. B. Determination of the reaction rate of DNA cleavage by Tg-AlkA. The amount of remaining substrate was plotted as a function of time by the single exponential decay equation to yield the best fit. CK: the reaction without the enzyme. 
Table 1 Oligonucleotides used in this study

\begin{tabular}{ll}
\hline Name & Sequence (5'-3') \\
\hline Tg-AlkA F & GGGAATTC $\underline{ }$ ATATGTTGATAGACCTTGAAAAAACG \\
Tg-AlkA R & CCCAAGCTTTCTCTTCCTCCTCTCCATCTC \\
Y139A F & AACCCGTTGGCGAGCTCGCCGCCTTTCCCACC \\
Y139A R & GCGAGCTCGCCAACGGGTTCTCCGGCGAGTTT \\
W204A F & TCCGCGGGATAGGGAAGGCGACGGCGGAGCTG \\
W204A R & GCCTTCCCTATCCCGCGGAACTTCGTGAGGTA \\
D223A F & CGTCTATCCAGCGGGAGCCCTGGGCCTGAGA \\
D233A R & GCTCCCGCTGGATAGACGTTTTTCCTCAGGC \\
W256A F & TCGAGCCCTATGGGAAGGCGAAGGGTTTGCTG \\
W256A F & GCCTTCCCATAGGGCTCGATGATTTCCCTAAC \\
p45 & Cy3CGAACTGCCTGGAATCCTGACGACXTGTAGCGAACGATCACCTCA \\
t45 & TGAGGTGATCGTTCGCTACYTGTCGTCAGGATTCCAGGCGTTCG \\
\hline
\end{tabular}

The underlined nucleotides are restriction sites.

The italic nucleotides represent the mutagenic base.

X: Hx, 1-meA, U, 8oxoG or AP site.

Y: G, T, C or A. 


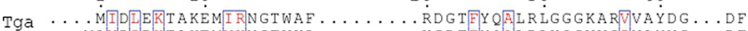

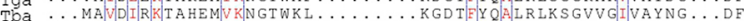
Tba $\ldots$ MAMIDIKKVTHEMIKNKTWKY $\ldots \ldots \ldots \ldots$ ERGIEW QALDYG $\ldots \ldots$ IVGFDGE. . NF

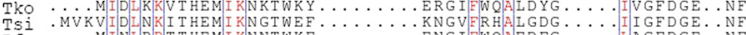

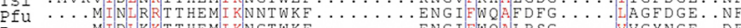

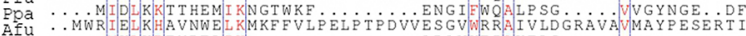

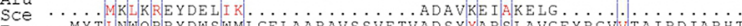

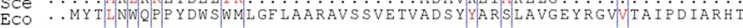
HSA MVTPALQMKKPKQFCRRMGQKKQR . . . . PARAGQPHSS SDAAQAPAEQPHSSSDAAQAP

50

60

70

80

90

100

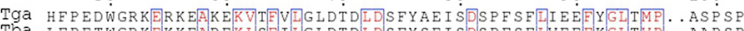
Tba LFPETWGRKEKKEAREKLSFILGLDTDLDSFYSEISDSPESFIVEEFKGLTUP. . AAPSP TKO YLPYYLSSKEKKDAKEKIKFILGLNTDLEREYGEIQDSKEAFIIEEFYGITVP. . AAPYK TSI YFPGYFSRKOOKEAKKKLEFVIGLNTDLEKFYSEIEDSKFAFIIKEFYGLTIP. . KAPDK

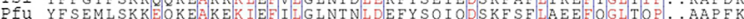

PDa TFPDHFGKREKKEAEERIRF I GLDTNLEKFYSEIQDSKFAFLVDEYGLTMP. . AAPTP

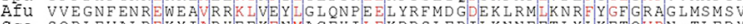
SCE SQPLEVALPEKYIARHEEKFNMACEHILEKDP S LFP I LKNNEETLYLKETQVPN. TLEDY

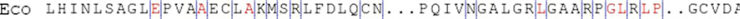
HSa CPRERCLGPPTTPGPYRSIYFSSPKGHLTRLGLEFFDPAVP ZARAELGQVLVRRLPNGT

110

120

130

140

150

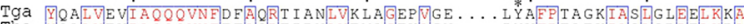

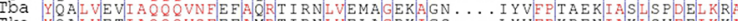

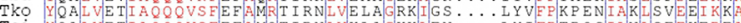
TSI YQALVETIAQQQVSEEFAMQT IRNLVKLAGKKLEN.... LYIEPTPQS ILNLSEEKFREA PfU YOALIETIAOOOVNE EFAMKT I GNEVKTFGKRVGE... . LYAEP SAEEVKNITIEOIKST

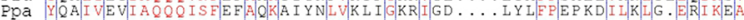

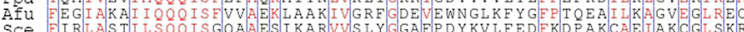

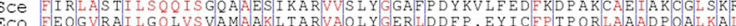

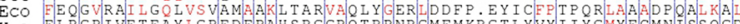

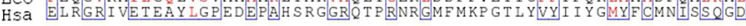

160

170

180

190

200

210

Tga RíGYRAGYIKSITESYIKGELNLEIWDWDIDEAIKYLTKERGIGKWTAELFLAYGLR. RN

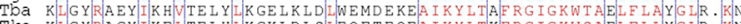

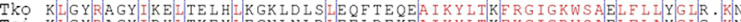

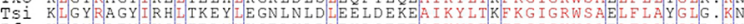
Pfu KFGYRAEYIKGLTELYVKGELKLDLEHLGEEES I KY LTRERG I GKW SAELFLA. Y GLR. KN Ppa KIGYRGDYILN TTEYWKGNLRIDIWELNEKDATKYLTKERGIGRWSAELFLMYGIR. KN Ppa R

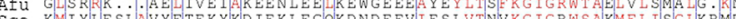
SCe KMIYIESLA.VY F TEKYKD IEKLFGQKDNDEEVIESLVTNVKG IGPWSAKMFLI SGLKRMD

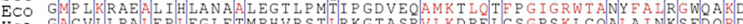

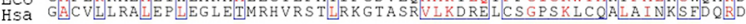

220

230

240

250

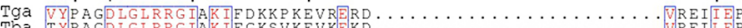

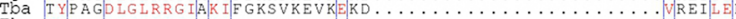

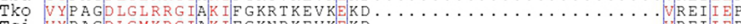

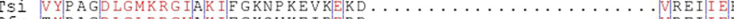

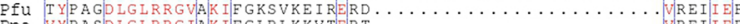

Ppa VYPASPLGLRRGIAKIFGLPLKKVTERT $\ldots \ldots \ldots \ldots \ldots \ldots$ VREIIIEP

SCE VEAPEDIGIARGESKYISDKPE

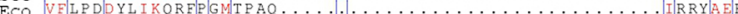

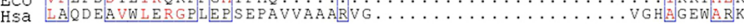

$$
\text { * } 260
$$

270

Tga YGKWKGITAFYTTCYDRKTEMERRKR .....

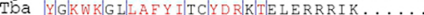

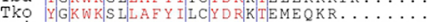

TSI YGKWKSLLAFYI LCYDRKIETVKKRGKN . . .

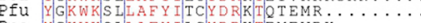

Ppa YGKWKSLLAFY I LCYDRKTEMEVRK . . . . . .

Afu EGREARDILFY LFLYDREFSKKTELV ....................

Sce FSPYRSVFMFILWRLAST NTDAMMKAEENFVKS

ECO WKPWRSYALLH TWYTEGWOPDEA

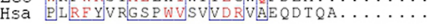
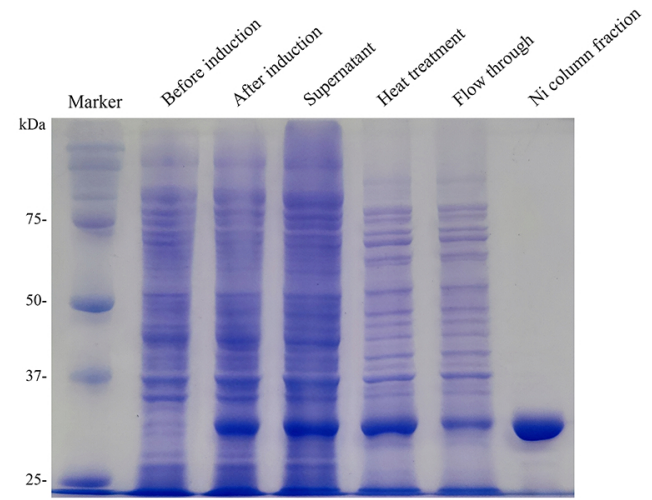
B

Tg-AlkA (nM) CK $\quad 200 \quad 400 \quad 600$

Cleavage (\%)

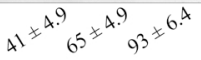

C $\begin{array}{lllll}\text { Tg-AlkA (nM) } & \text { CK } & 200 & 400 & 600\end{array}$

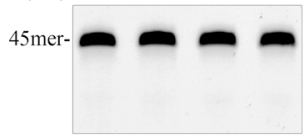

E

\section{$\mathrm{D}$}

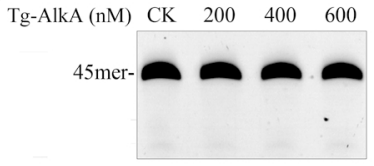

F

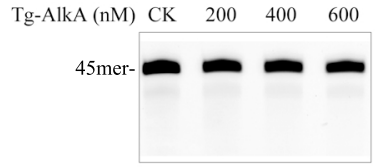

Cleavage (\%)
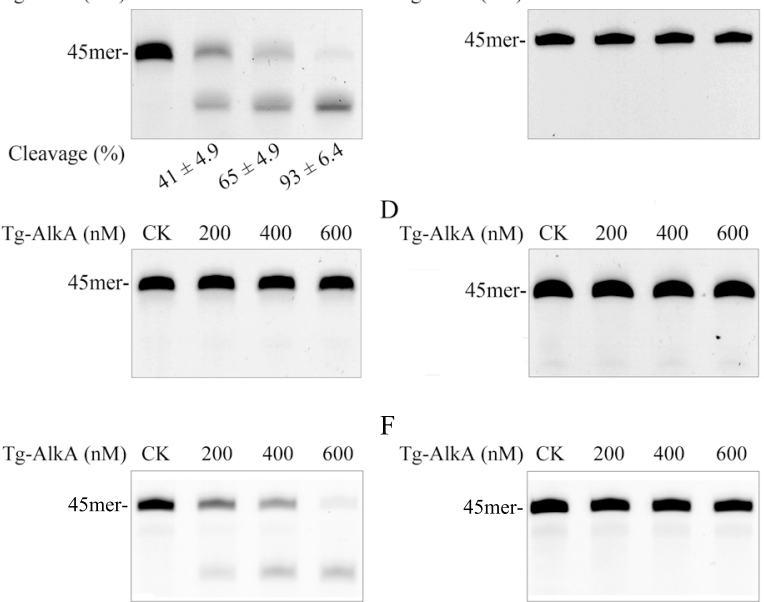

Tg-AlkA (nM) CK $\quad 200 \quad 400 \quad 600$

$$
2 x^{x^{5.1}} x^{5} x^{4.9} 77^{2.1}
$$




\section{A}

B

$\begin{array}{lllllllll}\text { Temperature }\left({ }^{\circ} \mathrm{C}\right) & \mathrm{CK} & 30 & 40 & 50 & 60 & 70 & 80 & 90\end{array}$

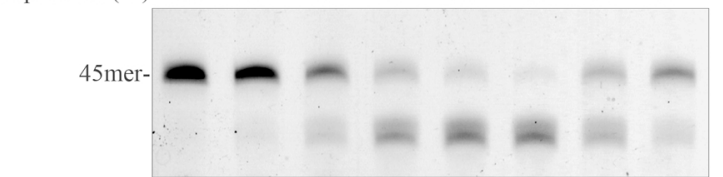

Cleavage $(\%)$

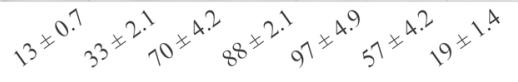

$\mathrm{C}$

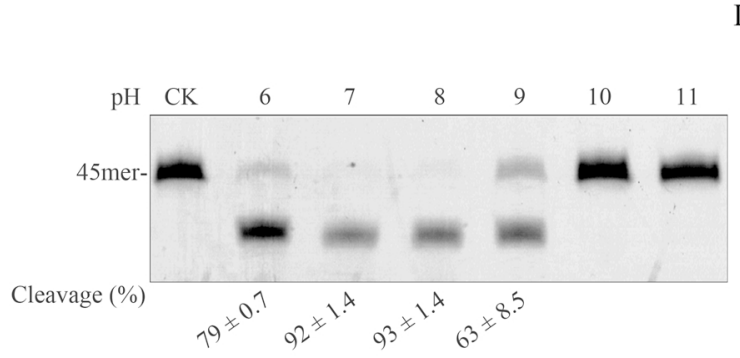

$\mathrm{D}$

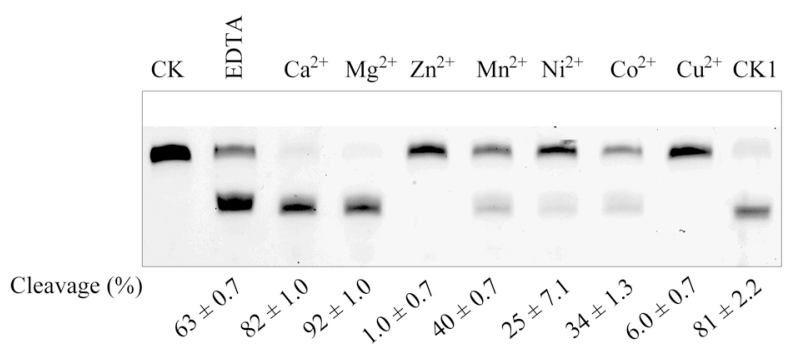

E

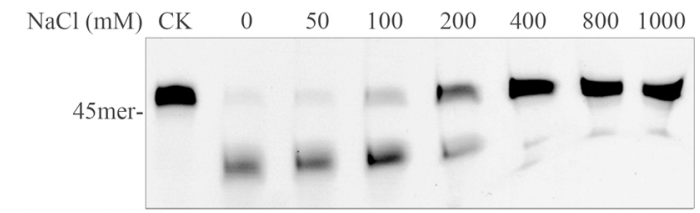

Cleavage $(\%)$

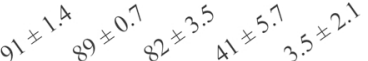

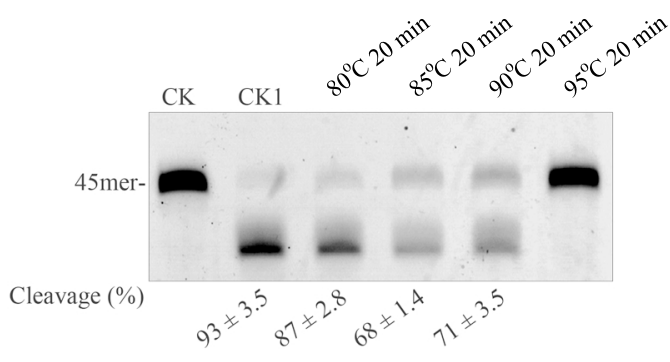




\section{CK Hx:T Hx:C Hx:G Hx:A}

Cleavage (\%)

$$
95^{x^{5}} 60^{x^{1.2}} 53^{x^{1 .}} 63^{x^{5 \cdot}}
$$

B

$$
\text { Tg-AlkA } \frac{\text { 8oxoG:C }}{-}+\frac{\mathrm{U}: \mathrm{G}}{-} \quad \frac{\mathrm{AP}: \mathrm{T}}{-+}
$$


A

Y139A (nM) CK $200 \quad 400 \quad 600$

W204A (nM) CK $200 \quad 400 \quad 600$

Cleavage (\%)

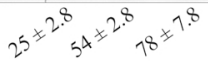

C D223A (nM) CK $\quad 200 \quad 400 \quad 600$

D
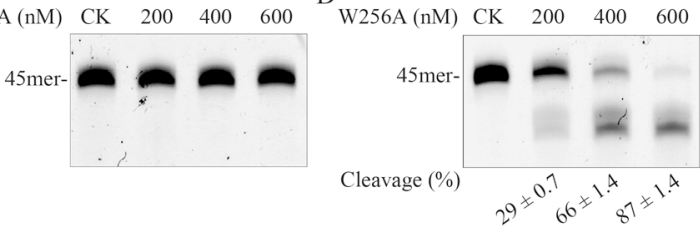
A

$\begin{array}{lllllllllll}\text { Reaction time (s) } & \mathrm{CK} & 10 & 20 & 40 & 60 & 120 & 300 & 600 & 1200 & 1800\end{array}$

Cleavage (\%)

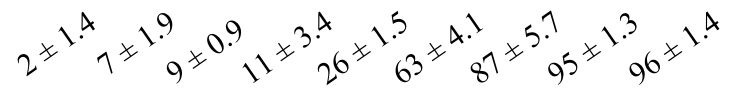

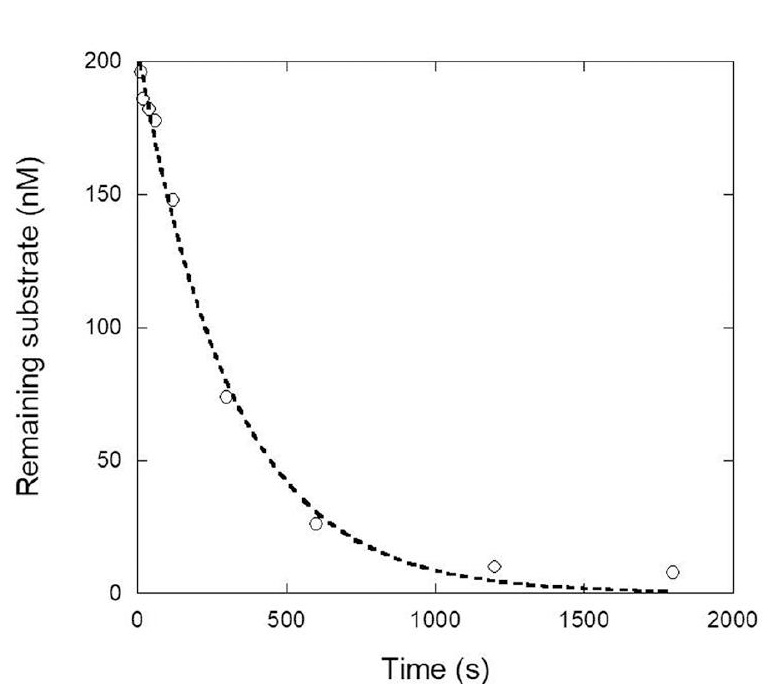

B

$45 \mathrm{mer}-$

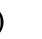

